The picture given by these combined rates is that mortality rose steeply among men, particularly among younger men, for whom the 1973 rates were about $80 \%$ higher than in 1950 . Among older men the rise was about $30 \%$. Among women, however, the trends were very different: mortality actually fell until the mid-1950s and rose thereafter only in the younger age groups. In fact over the whole 24 years studied there was no net increase in the death rate from heart disease among women. This surprising result emphasises the importance of a critical approach to all mortality statistics on ischaemic heart disease.

1 Clayton, D G, Taylor, D, and Shaper, A G, Health Trends, 1977, 9, 1.

2 Strasser, T, WHO Chronicle, 1974, 26, 451.

\section{Screening for tuberculosis}

Although Britain has now abandoned routine radiological screening for tuberculosis, occasional reports still remind us that we should not forget the highly susceptible in any population. Thus King and Geis ${ }^{1}$ have recently reported from the USA the consequences of the presence in a large urban prison in Chicago of a youth with infectious pulmonary tuberculosis. He had been confined to a cell block containing over 100 men and had had symptoms for at least a month. After his condition had been diagnosed $23 \%$ of the other inmates of this block were found to be tuberculin-positive compared with $15 \%$ of the rest of the prisoners. Three months later, however, $71 \%$ of those remaining in the cell block were tuberculinpositive and one had active disease.

It is unlikely that those contacts who had left prison in these three months could be followed up, and we should remember that similar risks in our prisons, mental subnormality hospitals, and other institutions still exist. Where the population changes slowly preventive measures are easier, but the solution to the problem must lie in screening for infectious cases in such circumstances. The value of this is shown by the results of monthly radiological surveys of two large prisons in England between 1971 and 1976, which disclosed $0.7-1.6$ potentially active cases of tuberculosis per 1000 of the population. This compares with between 0.12 and 0.15 per 1000 in surveys of the local general population in the same period. ${ }^{2}$

In our large cities Asian immigrants are the people most at risk of tuberculosis. ${ }^{3}$ Even scrupulous screening of them when they enter Britain will not prevent a high prevalence of tuberculosis continuing among them throughout their lives. So a programme of routine BCG vaccination at birth of all babies born in Britain to parents who came from countries with a high prevalence of tuberculosis is well justified. Since about a quarter of all cases of tuberculosis are first seen in general hospitals, ${ }^{4}$ there should be no relaxation of measures to protect the staff-including medical laboratory technicians, who are also at risk. ${ }^{5}$ Nor should the reverse risk be forgotten: of staff infecting patients, as in an outbreak of tuberculosis in a paediatric unit which resulted from an infected member of the staff. ${ }^{6}$

Some groups of persons have a higher than average risk of tuberculosis but are probably not significant sources of spread of infection. These include vagrants, alcoholics, and people with predisposing diseases, as well as men and women living alone (particularly in middle and later life). Thus, reporting a rise in the frequency of tuberculosis in the Potteries between 1971 and 1974 unconnected with immigration, Prowse and Cavanagh $^{7}$ ascribed this to a relative breakdown of control measures, in part owing to the closure of the smaller chest clinics. They proposed that bacteriological and pathological laboratories should start an automatic system of notifying tuberculosis to the main area chest clinics. In many areas notification of tuberculosis is done mainly by chest physicians -nominally to a non-existent medical officer of health but in practice to themselves and the tuberculosis health visitors. We need to ensure that administrative changes do not erode this still generally effective organisation. Some newly appointed respiratory physicians may be less experienced and less interested in the prevention of tuberculosis than their older colleagues, while some community physicians who are theoretically responsible may not have the experience to undertake the practical aspects of this work.

What advice can we seek on the control of tuberculosis today? There is the green booklet, on Tuberculosis: Epidemiology and Control, issued by the Department of Health and Social Security in $1973^{8}$ and the more recent paper by the American Thoracic Society ${ }^{9}$ on screening for pulmonary tuberculosis in institutions. The latter is carefully detailed and comprehensive, but British physicians might be more selective in the use of chemoprophylaxis and less inclined to use isoniazid alone than their American counterparts. We now have an acceptable alternative in combined preparations of isoniazid and ethambutol, which, though more expensive, are reliable and virtually free of side effects. Perhaps one question which neither document answers is how often a person in a closed community, known to be strongly tuberculin-positive, needs rescreening if for any reason he has not been given chemoprophylaxis. Certainly we should be wise not to forget that an old enemy may still threaten, albeit under new guises.

${ }^{1}$ King, L, and Geis, G, fournal of the American Medical Association, 1977,
237, 791.
2 McDowell, L A, personal communication, 1977.
${ }^{2}$ British Thoracic and Tuberculosis Association, British Medical fournal,
1975, 3, 698.
4 Morrison Smith, J, et al, Midland Medical Review 1964/66, 4, 255.
5 Harrington, J M, and Shannon, H S, British Medical fournal, 1976, 1, 759.
6 Stewart, C J, British Medical fournal, 1976, 1, 30.
7 Prowse, K, and Cavanagh, P, Lancet, 1976, 2, 357.
${ }^{8}$ Department of Health and Social Security, Tuberculosis: Epidemiology and
Control. London and Cardiff, HMSO, 1973.

American Thoracic Society, American Review of Respiratory Disease, 1977, 115,901 .

\section{Giardiasis}

Traditionally, doctors have regarded the cosmopolitan flagellate Giardia lamblia as comparatively benign. Yet, although most people carrying the parasite have no symptoms we now have increasing clinical and epidemiological evidence that $G$ lamblia may be an important pathogen in man. Since we last reviewed giardiasis, in $1974,{ }^{1}$ further outbreaks and infections have been reported from America, ${ }^{2-4}$ Australia, ${ }^{5}$ and Europe. ${ }^{6-9}$ Many infections have been acquired through travel abroad on Mediterranean cruises, to Leningrad, or to tropical countries, and $G$ lamblia is now the most common parasite imported into Britain. ${ }^{10} 11$ But these infections may be acquired without travel. In the Netherlands $7 \%$ of patients who had not travelled outside the country had stools containing 
G lamblia; and in those aged betwęen 5 and 9 years $21 \%$ of specimens were positive. ${ }^{9}$ In Glasgow the results of stool examination were positive in $13.3 \%$ of Scots children, compared with $10.2 \%$ of Asian and only $1.1 \%$ of Chinese or African children. ${ }^{12}$ The higher incidence of giardiasis in the indigenous population was attributed to severe overcrowding being greatest among the local Scots.

Why some people develop symptoms with giardiasis, and others do not, is not understood. Severe symptoms may occur when only a few parasites are apparently present, whereas slight or no symptoms may be present in individuals with massive numbers of parasites. Differences in host susceptibility may thus be important. The finding of circulating antibody to $G$ lamblia $^{13}$ may indicate either that mucosal invasion in giardiasis is more common than has been appreciated or that it indicates increased mucosal permeability with resultant absorption of parasite antigen. The possibility of synergism between enterobacteria and $G$ lamblia causing damage to the intestinal mucosa cannot be excluded. ${ }^{14}$

The incubation period of symptomatic giardiasis is usually about two weeks (in contrast to the more common type of travellers' diarrhoea, which starts within a few days of arriving abroad) but may be some months. The main complaint is usually diarrhoea-explosive, watery, or loose stools which may be bulky and offensive and are often passed only in the mornings; blood and pus are absent. Other symptoms include weakness, abdominal distension and discomfort, anorexia, nausea, weight loss, flatulence, vomiting, belching, depression, and, in children, failure to thrive. The acute stage may last from a few days to several months. Some people may have subacute symptoms lasting for months or years. In a recent review of 40 patients with clinical giardiasis, ${ }^{14}$ symptoms had been present for up to five years. Twenty-three of these 40 patients had impaired xylose absorption, 20 had low vitamin $\mathrm{B}_{12}$ absorption, and 15 had steatorrhoea. More severe malabsorption was associated with more appreciable histological abnormalities of the ileal mucosa.

Giardiasis should be suspected in all patients presenting with diarrhoea starting one or more weeks after travel, or persisting for one or more weeks whether they have travelled or not. Parasitological confirmation of the diagnosis may be difficult because the presence of $G$ lamblia cysts or trophozoites may be irregular and unpredictable. ${ }^{15}$ Intermittent passage of parasites in the stool may be related to periods of active multiplication, ${ }^{2}$ and examination of stools passed on alternate days allows for this periodicity. The patient may have symptoms for over a week before the parasite becomes detectable. ${ }^{8}$ Stool examination using a concentration method will kill the trophozoites and so give a false-negative result if the stool contains these forms only (a comparative rarity in clinical practice, but direct examination of a fresh stool is needed to detect trophozoites). Delays of several months between the onset of symptoms and the diagnosis are common. ${ }^{7}$ Some workers prefer mucosal smear biopsy to stool examination, ${ }^{716}$ but this is bothersome and time consuming. ${ }^{2}$ Unfortunately, the more simple technique of sampling duodenal contents by the Enterotest or Duocaps capsule with nylon yarn ${ }^{17-19}$ is not generally available in Britain. But, if he suspects giardiasis, the wise physician will give a course of specific treatment regardless of laboratory findings.

A three-day course of metronidazole, $2 \mathrm{~g}$ once daily, produced a parasitological cure rate of $91 \%$, whereas a 10 -day course of mepacrine, $100 \mathrm{mg}$ thrice daily, eradicated the parasite in only $63 \% \cdot{ }^{14}$ But sometimes mepacrine is more successful than metronidazole. ${ }^{20}{ }^{21} \mathrm{~A}$ single dose of tinadazole,
$1 \mathrm{~g}^{22}$ or $2 \mathrm{~g}^{23}$ has produced high cure rates, but this drug is not yet generally available in Britain. Having treated an individual, the doctor should then check the other members of the household, for some or all of these may also be infected. ${ }^{6}$

${ }^{1}$ British Medical fournal, 1974, 2, 347.

2 Wolfe, M S, fournal of the American Medical Association, 1975, 233, 1362.

${ }^{3}$ Schultz, M G, fournal of the American Medical Association, 1975, 233, 1383.

4 Hartong, W A, and Arvanitakis, C, fournal of the American Medical Association, 1977, 237, 1078.

${ }^{5}$ Simpson, G E C, Medical fournal of Australia, 1975, 1, 601.

${ }^{6}$ Willcox, M, British Medical fournal, 1975, 3, 101.

7 Eastham, E J, et al, Lancet, 1976, 2, 950.

8 Jokiph, A M M, and Jokiph, L, Lancet, 1977, 1, 1095.

${ }^{9}$ Meuwissen, J H E T, et al, Lancet, 1977, 2, 32.

${ }_{10}$ Ridley, D S, Fournal of Clinical Pathology, 1974, 27, 435.

11 Vella, E E, Lancet, 1977, 2, 33.

12 Goel, K M, et al, British Medical fournal, 1977, 1, 676.

${ }^{13}$ Ridley, M J, and Ridley, D S, Fournal of Clinical Pathology, 1976, 29, 30.

${ }^{14}$ Wright, S G, et al, Gut, 1977, 18, 343.

${ }^{15}$ Danciger, M, and Lopez, M, American Fournal of Tropical Medicine and Hygiene, 1975, 24, 237.

${ }^{16}$ Kamath, K R, and Murugasu, R, Gastroenterology, 1974, 66, 16.

17 Beal, C B, et al, American fournal of Tropical Medicine and Hygiene, 1970, $19,349$.

18 Thomas, G E, et al, South African Medical fournal, 1974, 48, 2219.

19 Palmer, R C, fournal of the American Medical Association, 1977, 237, 1078.

${ }^{20}$ Bassily, S, et al, fournal of Tropical Medicine and Hygiene, 1970, 73, 15.

${ }^{21}$ Babb, R R, et al, fournal of the American Medical Association, 1971, 217, 1359.

22 Salih, S Y, and Abdalla, R E, fournal of Tropical Medicine and Hygiene, $1977,80,11$.

${ }^{23}$ Pettersson, T, British Medical fournal, 1975, 1, 395.

\section{Ebola virus infection}

Some important questions raised by the outbreak last autumn in Southern Sudan and Zaire of a severe Marburg-fever-like illness need to be answered. What was the disease? What was its clinical picture and death rate? How did the outbreak start, spread, and finish-and why? What are the implications for control and containment of future infections? Finally, what should the doctor look for among patients with fever arriving in Britain or other non-tropical countries? We now have some facts about the outbreak and can answer some of these questions. ${ }^{12}$

The disease was caused by a virus morphologically indistinguishable from, but immunologically separate from, the Marburg virus-which was first isolated during the outbreak in that city in 1967 and later from the South African cases in 1975. It has been called Ebola virus from the name of the river and district initially affected in the recent outbreak.

Clinically the illness was severe, with a death rate of about half. The incubation period was from four to 16 days, after which patients had fever, headache, pains in the limbs and back, and then usually variable diarrhoea and vomiting. Pharyngitis and a dry cough were other common features. On the fifth day of the illness a rash appeared, as did a tendency to bleed from the gums, needle puncture sites, and elsewhere; jaundice was not seen. In pregnant women abortion and massive uterine haemorrhage were common. Those who died did so between the fourth and tenth day and in those who survived recovery was slow. Treatment was mostly supportive, but the reports suggest that immune plasma may be of benefit and interferon has been tried.

Epidemiologically, the outbreak appears to have started with a traveller, but how he contracted it is unknown. He trans- 